\title{
ANTIGUIDADE ORIENTAL NO BRASIL: RELATOS DE PESQUISA DO “LEAO"
}

\begin{abstract}
Katia Pozzer*
Recebido em: 23/10/2019

Aprovado em: 31/10/2019

ORIENTAL ANTIQUITY IN BRAZIL: “LEAO” RESEARCH REPORTS
\end{abstract}

* Professora Adjunta do Instituto de Artes e do Programa de Pós-Graduação em História, Universidade Federal do Rio Grande do Sul.

katia.pozzer@ufrgs.br
$1 \begin{aligned} & \text { participação do Laboratório de Estudos da Antiguidade Oriental } \\ & \text { (LEAO) no "I Seminário dos Grupos de Estudo da } \\ & \text { Sociedade Brasileira de Estudos Clássicos" teve como }\end{aligned}$ objetivo principal visibilizar a produção científica do LEAO e articular sua atuação junto aos demais núcleos brasileiros, bem como consolidar a UFRGS como um polo de pesquisa na área dos estudos da Antiguidade no Brasil. O LEAO, criado em março de 2017, está vinculado ao Programa de Pós-graduação em História e ao Departamento de Artes Visuais da Universidade Federal do Rio Grande do Sul e tem como foco a pesquisa da antiga Mesopotâmia, ao longo dos três mil anos de história, e sua relação com as demais civilizações do Antigo Oriente Próximo. O grupo propõe o debate e a reflexão crítica sobre a história antiga oriental, discutindo questões contemporâneas e lançando um novo olhar sobre um passado do qual conservamos uma importante herança cultural.

O Laboratório de Estudos da Antiguidade Oriental (LEAO) tem ainda como objetivo a difusão das pesquisas sobre a Mesopotâmia, em particular, e sobre o mundo antigo, em geral, estimulando a publicação de artigos, capítulos de livros, resenhas, bem como a participação em eventos científicos no Brasil e no exterior. O grupo visa à formação de novos pesquisadores na área de história antiga oriental, promovendo a participação de estudantes nos diversos níveis de formação, desde a iniciação científica até a pós-graduação stricto sensu.

O LEAO está articulado com a linha de pesquisa História, Arte e Memória Cultural, que busca compreender as relações entre a história, a memória, a produção de imagens artísticas e a formação de tradições culturais. Entendemos que as imagens existem sobre 
suporte material, são produtos históricos de seu tempo, feitos de matéria e transmitidos como patrimônios, acervos e linguagens.

No site do LEAO (www.ufrgs.br/leao) divulgamos um breve currículo dos membros do grupo, notícias e eventos relacionados aos estudos de antiguidade e nossa lista de parceiros. O LEAO busca o diálogo com diferentes especialistas no cenário acadêmico brasileiro e internacional e tem, atualmente, parceria com vários grupos de pesquisa, que podem ser visualizados em http://www.ufrgs.br/leao/links.

Além disso, também estão disponíveis as publicações on-line do grupo de pesquisa, uma breve resenha dos projetos de pesquisa já realizados e os que estão em andamento e links de interesse para sites contendo documentação sobre o mundo antigo oriental (http:// www.ufrgs.br/leao/links-de-interesse).

\section{Projeto Arte, História e Cultura Material - um estudo de selos-Cilindros}

Atualmente está em desenvolvimento o projeto de pesquisa intitulado Arte, História e Cultura Material - um estudo de selos-cilindros, que conta com o apoio da PROBIC/ UFRGS, CNPq e FAPERGS e tem a participação de graduandos dos cursos de História e de História da Arte. O estudo tem por objetivo investigar a iconografia e as inscrições cuneiformes dos selos-cilindros pertencentes às diversas tradições mesopotâmicas na região do Oriente Próximo, dentro de uma perspectiva multidisciplinar, articulando a história da arte, a arqueologia e a história. Propõe-se a discussão do uso da cultura material, enquanto imagem-documento, bem como o aporte teórico da iconologia e de suas contribuições para as pesquisas em História da Arte antiga, além do deciframento e tradução das inscrições constantes nestes selos.

O plano prevê a análise de temas, como as figuras antropomorfas e geométricas, os animais (reais e imaginários), a vegetação e a paisagem, a arquitetura, as divindades, a representação feminina, os símbolos e os atributos, bem como inúmeras referências a temas literários. Quanto ao recorte temporal e geográfico, incluímos documentos de um amplo leque cronológico, do II milênio AEC até meados do I milênio AEC, isto é, do período paleobabilônico até a conquista persa na Mesopotâmia. A delimitação espacial engloba a Baixa e a Alta Mesopotâmia, mais especificamente, a região da Babilônia e da Assíria, impérios proeminentes do período.

Do ponto de vista da História, as fontes iconográficas e a cultura material são plenas de revelações históricas, desde que tratadas com metodologias adequadas. Já da perspectiva dos estudos no campo da história da arte, as imagens são portadoras de concepções estéticas, ideológicas, políticas e sociais.

A disciplina de História da Arte possui mérito próprio, na qual a estética é um campo de investigação legítimo, baseado na sensibilidade e na razão. Segundo Ulpiano Bezerra de Meneses (2005, p. 33), a história visual é um campo de operação de grande valor estratégico para o conhecimento histórico da sociedade, de sua organização, funcionamento e transformação. Desta forma, consideramos que a dimensão visual está presente no todo 
social e que a sua interpretação seja necessária, justificando, assim, a escolha da temática de pesquisa.

Para a disciplina histórica, os estudos da nova história cultural desempenharam um papel fundamental no sentido de elevar as imagens à categoria de fontes históricas de primeira grandeza (Burke, 2016).

No Brasil, essa corrente teórica/historiográfica vem ganhando espaço nos trabalhos acadêmicos e em eventos nacionais de âmbito multidisciplinar. Mais recentemente, assistimos no Brasil à criação de cursos de graduação em História da Arte nas universidades públicas brasileiras, como um importante fomento e ampliação do campo dos estudos visuais no país, ainda que as pesquisas em arte antiga sejam em número bastante reduzido.

Sabemos que a cultura material é portadora de determinadas mensagens que a linguagem escrita não é capaz de transmitir. A habilidade da arte em representar mensagens torna-a uma poderosa ferramenta de persuasão da qual um grupo pode dispor. Ela referese à forma que os signos podem tomar e quais os sentidos e valores a ela atribuídos para reproduzir o poder social dominante. A iconografia revelada pelos objetos demanda um estudo específico, pois encontramos, na Antiguidade, textos acompanhados por imagens (Amiet, 1979, p. 8). Os artistas antigos criaram um repertório que compreende diversos tipos de cenas e de personagens, cuja identificação é rica de significados (Bustamante, 2003). As imagens são representações de ideais, sonhos, medos e crenças de uma época. Logo, são, elas próprias, fontes históricas e, sendo assim, material para a análise e a interpretação histórica.

Os selos-cilindros, as placas de marfim esculpidas e os tijolos esmaltados foram os produtos mais importantes da produção artística da Mesopotâmia. Eles estiveram presentes, em grande número, em todas as culturas do Oriente Próximo e contribuíram muito para a compreensão destas antigas civilizações.

Um dos critérios para as datações da arte mesopotâmica é o desenvolvimento dos estilos e dos motivos da glíptica. Além disso, as figuras e as cenas representadas oferecem uma matéria rica para a interpretação arqueológica. As referências cronológicas são seguras quando o nome de um soberano é gravado sobre o selo. Uma outra possibilidade de se datar, bastante frequente, é quando um selo foi desenrolado em um tablete contendo uma inscrição e uma datação (Frankfort, 1996, p. 35).

A comparação entre texto e imagem constitui um elemento essencial da pesquisa sobre imagens antigas, assim como das ciências humanas em geral. No passado, texto e imagem foram percebidos como meios de expressão concorrentes, com hierarquia entre eles. Atualmente, entende-se que texto e imagem devam ser analisados a partir de uma concepção dialógica e interativa, mais do que hierárquica. O diálogo entre texto e imagem possibilita uma compreensão mais complexa da mensagem, sobretudo quando tratamos das civilizações antigas. Elas nos legaram inúmeros testemunhos onde imagem e texto são combinados diretamente sobre um mesmo suporte, explorando a troca entre a comunicação linguística-verbal e a visual.

Esta visão dialógica e interativa é fundada nas práticas pretéritas que justapunham palavras e imagens. Os antigos acreditavam que cada enunciado poderia evocar uma imagem 
no espírito de cada espectador/ouvinte. A imagem também poderia ser acompanhada de um texto, onde o espectador desempenhava um papel central (Muth et al., 2012, p. 220).

Constata-se, pois, uma diferença radical entre as experiências, as visualidades e as ontologias antigas e contemporâneas da imagem. Os antigos tinham uma percepção das imagens muito diferente da nossa, eles não as viam como imagens, mas como agentes ou seres divinos.

A discussão sobre o status da representação visual na Mesopotâmia é uma questão fundamental para a história da arte do Antigo Oriente Próximo. A noção axiomática de que a representação é um meio de imitação de coisas reais do mundo deve ser descartada para entendermos a arte da antiguidade oriental. Eles acreditavam no poder dos significantes e de seu status como parte integrante do real (Bahrani, 2003, p. 122).

A imagem na antiga Mesopotâmia não é considerada como semelhante a uma realidade original que está presente em outro lugar, mas ela contém a realidade em si mesma (imagem). A razão para que esta noção de representação seja possível para assírio-babilônicos é que o domínio do real inclui, por definição, múltiplas camadas e um complexo sistema de signos que Bahrani (2003, p. 127) descreve como "realmetasemiótico" e opõe ao metafísico.

\section{AS FONTES DE PESQUISA}

A partir da segunda metade do IV milênio AEC, passaram-se a imprimir seloscilindros nos tabletes como garantia de sua autenticidade. Esses selos, como o seu nome indica, possuíam forma cilíndrica e eram confeccionados em pedra, cerâmica, vidro, argila cozida, madeira, marfim ou metal. Eram esculpidos com motivos iconográficos da mitologia e da vida cotidiana dos mesopotâmicos, representando uma importante fonte documental sobre a história desta civilização. O termo sumério para o gravador de selo era BUR.GUL e em acádico purkullu.

Existem duas formas mais comuns de selos no antigo Oriente Próximo. O mais antigo e mais difundido foi o selo tipo carimbo (Fig. 1). O selo-cilindro surge no período de Uruk, no IV milênio AEC e precede a invenção da escrita (Fig. 2). 
FIGURA 1 - Selo carimbo e Impressão moderna. Inscrição de fundação de um templo. Reinado de Narâm-Sîn, séc. XXIII AEC. Argila. British Museum, Londres, Inglaterra.

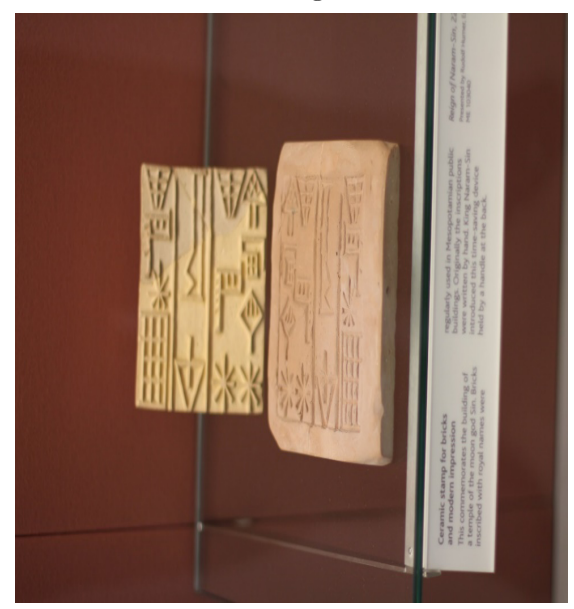

Foto da autora

FIGURA 2 - Selo carimbo e Impressão moderna. Figura feminina nua, gênio entre dois grifos?? Período assírio. Quartzo rosado.

Vorderasiatisches Museum, Berlim.

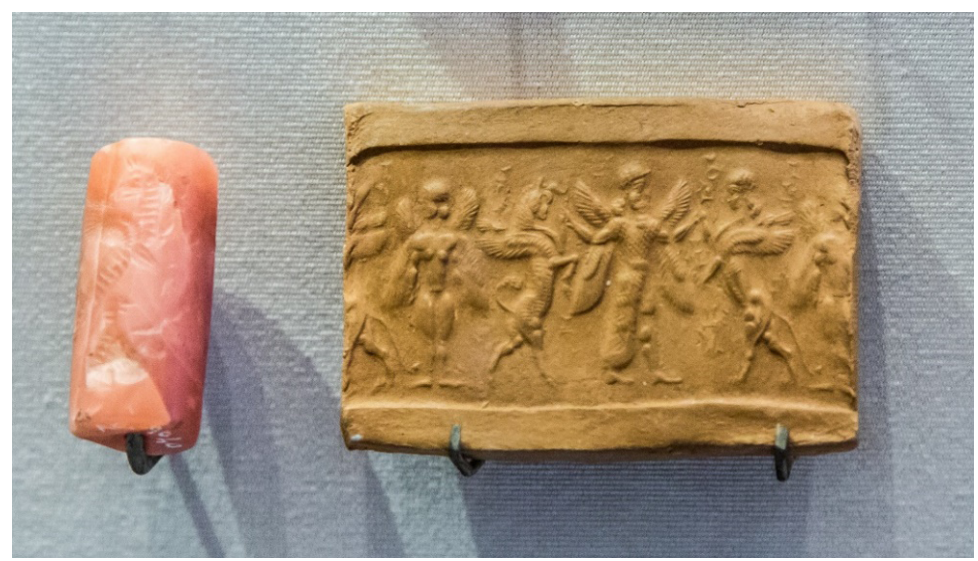

Foto da autora

A característica básica associada aos selos é a sua capacidade de fazer uma marca reconhecível a partir da imagem gravada em sua superfície. O processo de gravação é chamado de "entalhe".

O motivo representado sobre os cilindros consistia geralmente em cenas figuradas e seu uso era o signo distintivo de uma classe social elevada, como os reis, os escribas, os mercadores, os homens de negócio. Cada motivo era único e imutável. O motivo era gravado vazado na superfície do cilindro e esta é a razão pela qual se designa esta arte pelo termo de glíptica. Quando se desenrola o selo, a imagem aparece em positivo. 


\section{UM EXERCÍCIO DE ANÁLISE ICONOGRÁFICA}

Apresentamos abaixo algumas imagens da impressão dos selos-cilindros com uma breve descrição das mesmas para exemplificarmos a análise proposta (Figs. 3 e 4).

Alguns temas têm uma longa história, como a cena da "introdução" (Hrouda, 1992, p. 222), onde um orante é introduzido por uma divindade secundária em presença de um deus mais importante. Esta cena reproduziria um cerimonial de culto típico do templo.

FIGURA 3 - Selo-cilindro e Impressão moderna de Haš-hamer, governador de Iškun-Sîn, reinado de Ur-Nammu (2112-2095 AEC) Pedra Esverdeada, Argila, (5,3 X 3,03 X 2,87 cm). British Museum, Londres, Inglaterra.
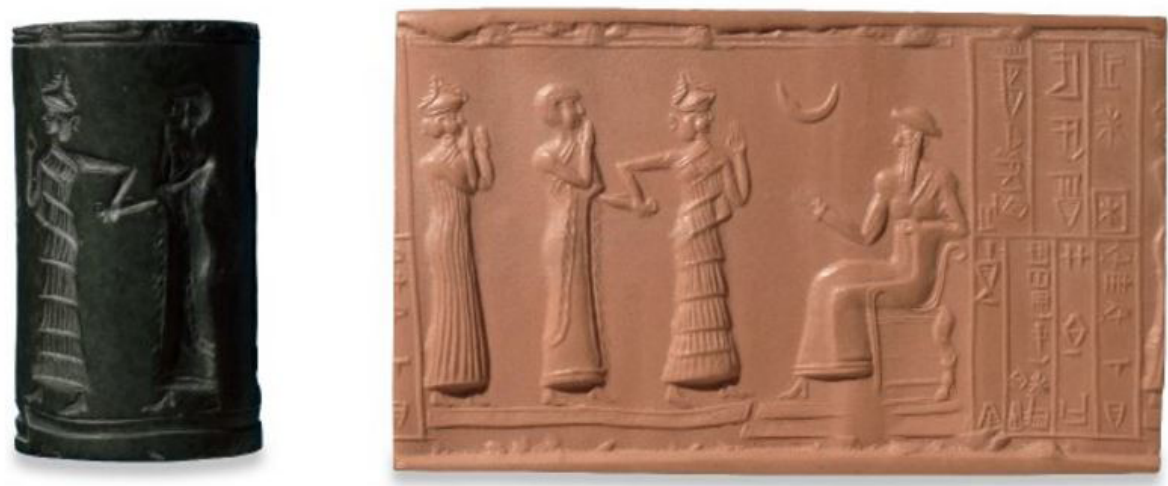

FIGURA. 4 - Detalhe. Impressão de selo-cilindro de Haš-hamer, governador de Iškun-Sîn, reinado de Ur-Nammu (2112-2095 AEC)

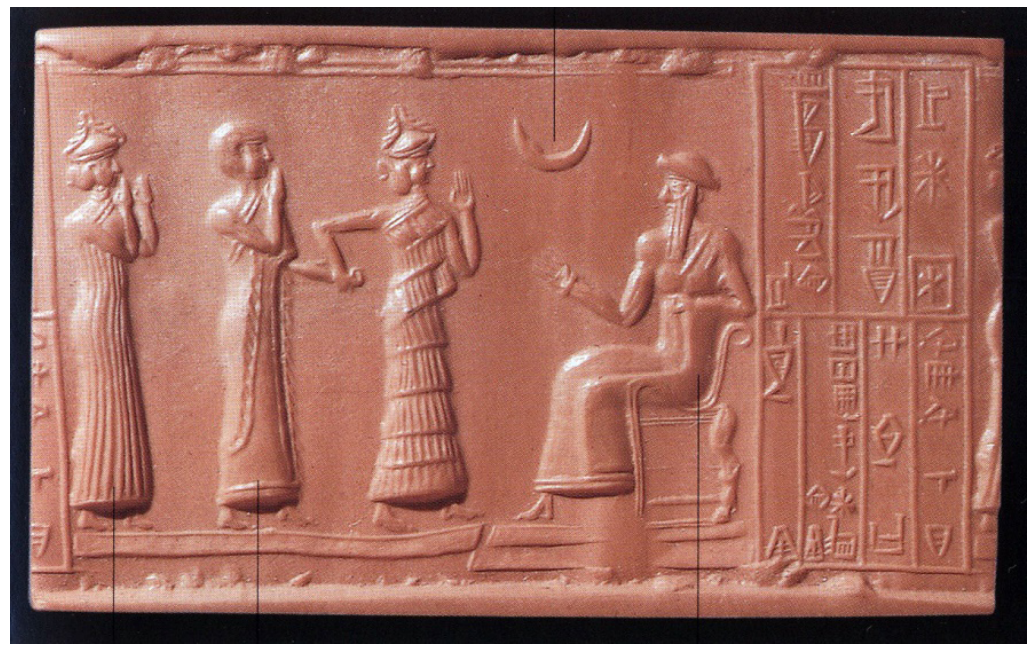

Fonte: Ascalone, 2006, p. 131. 
As figuras 3 e 4 mostram o selo-cilindro de Hašhamer e sua impressão moderna em argila. Da esquerda para a direita, há uma divindade feminina, com um diadema com chifres, uma túnica longa e os antebraços erguidos na frente do corpo, em um gesto de súplica. Diante dela temos a figura do orante que é apresentado por uma divindade feminina, que segura seu pulso. Ela possui um diadema com chifres, uma túnica longa com franjas por todo o corpo, tratando-se, presumivelmente, de Lamma. Essa figura também apresenta os antebraços erguidos na frente do corpo, em um gesto de súplica, que não é exclusivo das representações dos selos-cilindros.

Diante de Lamma, geralmente evocada como introdutora dos fiéis na presença de divindades importantes, temos um personagem masculino, com kaukanés e franjas no acabamento da saia, usando uma touca real. Esta figura está sentada em um trono, sobre uma plataforma. É possível observar o detalhe da perna da cadeira em forma de pata de leão que nos faz presumir que este é o rei, aqui identificado por suas roupas e atributos. A figura tem o braço direito levantado para a frente e o rosto está voltado para a comitiva.

A lua crescente, presente no campo visual, diante do rei, evoca o deus Sîn, a divindade mais importante do panteão de Ur. Haš-hamer, governador de Iškun-Sîn, vestido com uma longa veste, ornada com franjas, levanta o braço direito em sinal de reverência ao rei. Ele é introduzido diante de Ur-Nammu por uma divindade secundária que veste um kaukanés, ombro desnudo, tiara de cornos. Todos os deuses são retratados usando a tiara de chifres, o principal atributo das divindades. Ur-nammu está sentado no trono com espaldar, com detalhe da perna em forma de pata de leão, possui uma longa barba, veste comprida e tem a touca real. O leão é um animal associado à realeza, com simbolismo de força. A presença de uma quarta figura é rara nestas cenas, trata-se de outra divindade feminina secundária, também vestida com um longo kaukanés e as duas mãos em posição de reverência. A inscrição cuneiforme, em duas colunas, diz: sur-nammu, nita kala-ga, lugal uri-ma ha-aš-ha-me-er, ensi, iš-ku-en-EN.ZU ìr-zu, que pode ser traduzido por Ur-Nammu, homem forte, rei de Ur, Haš-hamer, governador da cidade de Iškun-Sîn, é seu servidor.

A inscrição presente no selo-cilindro nos permite identificar o personagem orante. Trata-se de Haš-hamer, o governador da cidade de Iškun-Sîn, uma figura política importante no período. $\mathrm{O}$ artista que executou o selo tinha pleno domínio da técnica de confecção do mesmo. Ele optou por grande clareza no campo visual, sem, contudo, abrir mão dos detalhes, como a pata do leão no pé da cadeira com espaldar alto, o trono do rei Ur-Nammu. Uma única menção a uma divindade estelar é a lua crescente, simbolizando o deus Sîn, o mais importante do panteão de Ur, cidade-estado com poder hegemônico no período.

Os reis de Ur herdaram muitas práticas de seus predecessores de Akkad, como os títulos reais, o conceito de Estado mesopotâmico, assim como a forma de administração. A extraordinária documentação textual referente à administração de Ur revela aspectos jurídicos, grandes construções, canais de irrigação e diques, assim como a quantificação de homens deslocados para uma determinada obra pública, censos de animais, recebimento de impostos em forma de cerveja, pães, óleos e peixes. Isto nos evidencia o controle que o Estado tinha sobre quase tudo o que se produzia em Ur e em seus arredores. 
Podemos ressaltar, ainda, que os reis da terceira dinastia de Ur contribuíram decisivamente no âmbito da cultura da antiga Mesopotâmia, através de seus importantes programas de construções de obras públicas de caráter monumental, que tanto influenciaram o surgimento dos primeiros zigurates (Pozzer, 2013, p. 52).

Neste selo temos imagens que evocam súplicas por favores divinos, prática altamente atestada nas fontes mesopotâmicas antigas, onde muitas das cenas evocam gestos de afeto e/ou cumplicidade entre reis e deusas.

Por vezes os selos eram acompanhados de inscrições, contendo o nome do proprietário, sua filiação e indicação do deus de sua devoção particular. Ainda que haja dificuldade em interpretar algumas destas cenas, é possível reconhecermos as divindades e as identificarmos quando são acompanhadas pelos seus atributos que conhecemos através de outros documentos. Os selos representam uma importante fonte documental sobre a história desta civilização e seu uso era o signo distintivo de uma classe social elevada, como a dos reis, os escribas, os mercadores, os homens de negócio, onde cada motivo era único e imutável.

Podemos ainda dizer que a associação entre as inscrições e as imagens demonstra a troca entre duas formas de comunicação: a verbal-linguística e a visual e, uma vez entendida a partir de uma concepção dialógica e interativa entre elas, pode contribuir eficazmente para a compreensão da mensagem.

Como objeto, o selo era portador de significados, símbolo de poder, de autoridade e de status social. Eles poderiam servir como oferendas votivas ou funerárias, como presente aos deuses ou, ainda, como amuletos protetores (Pittman, 2006, p. 1589). Os selos tiveram um importante papel na economia e na administração e ainda testemunharam a influência e a difusão de diferentes culturas no antigo Oriente Próximo.

\section{REFERÊNCIAS}

AMIET, P. Introduction à l'histoire de l'art de l'antiquité orientale. Paris: Desclée de Brouwer, 1979. AMIET, P. Le Symbolisme Cosmique du Répertoire Animalier en Mésopotamie. Revue d'Assyriologie et d'archéologie orientale, v. 50, n. 3, 1956, p. 113-126.

ASCALONE, E. Guide des Arts - La Mésopotamie. Paris: Hazan, 2006.

ASHER-GREVE, J. Women and agency: a survey from Late Uruk to the end of Ur III. In: H. CRAWFORD (Ed.). The Sumerian World. London: Routledge, 2013, p. 359-377.

BAHRANI, Z. Women of Babylon. New York: Routledge, 2001.

BAHRANI, Z. The Graven Image - Representation in Babylonia and Assyria. Philadelphia: University of Pennsylvania Press, 2003.

BAHRANI, Z. Rituals of War- The body and violence in Mesopotamia. New York: Zone Books, 2008. 
BELL, Julian. Uma Nova História da Arte. São Paulo: Martins Fontes, 2008.

BEZERRA DE MENESES, U. T. Fontes visuais, cultura visual, História visual. Balanço provisório, propostas cautelares. Revista Brasileira de História. v. 23, n. 45, 2003, p. 11-36.

BEZERRA DE MENESES, U. T. Rumo a uma "História Visual”. In: MARTINS, J. S.; ECKERT, C.; NOVAES, S. C. O imaginário e o poético nas Ciências Sociais. Bauru: EDUSC, 2005. p. 33-56.

BLACK, J.; GREEN, A. Gods, Demons and Symbols of Ancient Mesopotamia. London: British Museum Press, 1998.

BLACK, J.; GEORGE, A.; POSTGATE, N. A concise dictionary of Akkadian. Wiesbaden: Harrassowitz Verlag, 2000.

BOTTÉRO, J. L'Écriture, la raison et les dieux. Paris: Gallimard, 1987.

BURKE, P. O que é história cultural? Rio de Janeiro: J. Zahar, 2005.

BURKE, P. Testemunha Ocular. São Paulo: UNESP, 2016.

BUSTAMANTE, R. M. C. Representações visuais das mulheres nos mosaicos norte-africanos baixo-imperiais: isotopia e gênero. Phoinix, v. 9, 2003, p. 314-359.

CURATOLA, G. L'Art en Mésopotamie. Paris: Hazan, 2006.

FRANKFORT, H. The Art and Architecture of the Ancient Orient. New Haven: Yale University Press, 1996.

GLASSNER, J.-J. La Mésopotamie. Paris: Les Belles Lettres, 2002.

HROUDA, B. L'Orient Ancien- histoire et civilisations. Paris: Bordas, 1992.

HUYS, V.; VERNANT, D. Histoire de L'Art. Théories, Méthodes et Outils. Paris: Armand Colin, 2015.

JANSON, H. W. História Geral da Arte. O Mundo Antigo e a Idade Média. São Paulo: Martins Fontes, 2007.

JOANNÈS, F. (Org.). Dictionnaire de la Civilisation Mésopotamienne. Paris: Robert Laffont, 2001.

LEAO. Laboratório de Estudos da Antiguidade Oriental. Disponível em: http://www.ufrgs.br/ leao. Acesso em: 30 ago. 19.

MARCUS, M. Art and Ideology in Ancient Western Asia. In: SASSON, J. M. (Ed.). Civilizations of the Ancient Near East. Peabody: Hendrickson Publishers, 2000. p. 2487-2505.

MUTH, S. et al. Texte et image dans l'Antiquité: lire, voir et percevoir. Perspective, v. 2, 2012. Disponível em: http://perspective.revues.org/145.

PANOFSKY, E. Estudos de Iconologia. Lisboa: Editorial Estampa, 1995.

PANOFSKY, E. Significado nas Artes Visuais. São Paulo: Perspectiva, 2007. 
PEIRCE, C. S. Semiótica. São Paulo: Perspectiva, 2000.

PITTMAN, H. Cylinders Seals and Scarabs in the Ancient Near East. In: SASSON, J. M. (Ed.). Civilizations of the Ancient Near East. Peabody: Hendrickson Publishers, 2000, p. 1589-1603. POZZER, K. M. P. (Org.). História Antiga Oriental. Canoas: ULBRA, 2013.

WINTER, I. J. On Art in the Ancient Near East. Leiden: Brill, 2010. v. 1. 